\title{
A Study on Golden Age for Vietnamese Learners of English
}

1 Ho Chi Minh City University of Food Industry; tranngocthanhtuyen1107@gmail.com

* Correspondence: tranngocthanhtuyen1107@gmail.com; Tel.: 03580165570

\begin{abstract}
When starting learning English, Vietnamese learners will often meet with some difficulties caused by the influence of both external and internal factors. One of the most important internal factors that affect language acquisition is the age factor; therefore, finding the golden age for Vietnamese learners of English will contribute to declining some troubles that can meet for beginners. This study is performed based on a combination of qualitative methods and quantitative methods, which aims to provide the most accurate results in this issue. First, the qualitative methods are applied through searching, analyzing, and synthesizing some studies related to this topic on the Internet via two main websites, Google Scholar and Google Book. Second, the quantitative methods are executed through two main forms: online survey via Google Form and interview via Zalo and Messenger. Through the study, it is concluded that the golden age ranges from ages three to under 18 years old; in this period, people can reduce to the lowest level of the problems relating to four skills in English, especially listening and speaking skills. Besides, the study finds out that different ages of learning English would lead to differences in some respects like vocabulary learning speed, English listening comprehension, grammar knowledge, etc.
\end{abstract}

Keywords: golden age; qualitative methods; quantitative methods; learning English

\section{Introduction}

Age is one of the important factors that affect the learning English of the people living Citation: Tuyen, T.N.T. (2021, Au-
gust 22). A Study on Golden Age for Vietnamese learners of English. https://osf.io/pre-

prints/socarxiv/gwby9/

Academic Editor: Tuyen Tran Ngoc Thanh

Received: 2021, August 17 Accepted: 2021, August 22 Published: 2021, August 22

Publisher's Note: MDPI stays neutral with regard to jurisdictional claims in published maps and institutional affiliations.

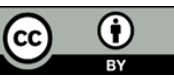

Copyright: (c) 2021 by the authors. Submitted for possible open access publication under the terms and conditions of the Creative Commons Attribution (CC BY) license (https://creativecommons.org/licenses/by/4.0/). in countries that English is not a mother language, including Vietnam. The age factor is the object that many researchers studied such as David Michael Singleton, Lisa Ryan (2004), Eric H Lenneberg (1967), etc. Basically, all concluded that second language (bilingual language) in general and English in particular should be learned early, the reason is that neuromuscular mechanisms work most actively during childhood (Lenneberg, 1967, Nghi, 2020, \& Nghi,2016). On the other hand, learning English so late will be more difficult due to many other influencing factors outside of age such as learning environment, time, emotion, etc. That is why it is easy for many people to feel bored and think that English is ridiculously hard. So, specifically when is it called a golden time or golden age to learn a new language?

The study aims to discover the best age to be able to acquire a new language (English) and the reason for that. Next, it is also hoped to be able to contribute to changing the mindset of a part of people who thought English was problematic to learn.

\section{Literature review}

\subsection{The definition of "Golden Age" in general}

"Golden Age" is the phrase defined in many ways. For example, according to Cambridge Dictionary, "Golden Age" is a period, sometimes imaginary, when everyone was happy, or when a particular art, business, etc. was remarkably successful. On the other hand, Merriam-Webster defined the "Golden Age" as a period of great happiness, prosperity, and achievement, etc.

2.2. Golden Age and Foreign Language acquisition
6 
In linguistics, Golden age is the period that the human brain's development is the most rapidly; therefore, people can remember as well as rehearse facts most effectively leading to language acquisition happened easier, it is also called as Critical Period.

Foreign language acquisition (FLA) is the process that human study a new language or second language, which is completely different from mother language (Phuc et al, 2019). And the foreign language mentioned in this study is English, and the object is Vietnamese learners.

\subsection{The definition of Critical Period Hypothesis ( $\mathrm{CPH}$ )}

The Critical Period Hypothesis was first proposed by Montreal neurologist Wilder Penfield and co-author Lamar Roberts (1959), and was popularized by Eric Lenneberg (1967). The Critical Period Hypothesis is that the subject of a long-standing debate in linguistics and language acquisition over the extent to which the power to accumulate language is biologically linked to age. In its most succinct and theory-neutral formulation, $\mathrm{CPH}$ states that there is a limited development period during which it is possible to accumulate a language, be it mother tongue or second language, to normal, nativelike levels (Birdsong, 1999, Nghi, 2020).

\subsection{Children, Adults, and second language acquisition}

The question of whether a child or an adult learns a second language better is still mysterious, although many researchers show that children are more receptive to a new language than adults. For example, Lenneberg's CPH $(1967$, p. 62) shows that the process of language acquisition can only happen to range from 2 to under puberty (that is mean in critical period) (see Figure 1).

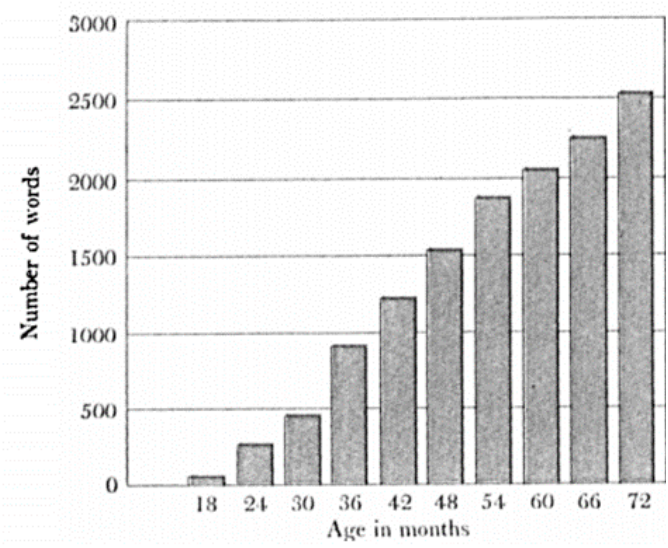

(a)

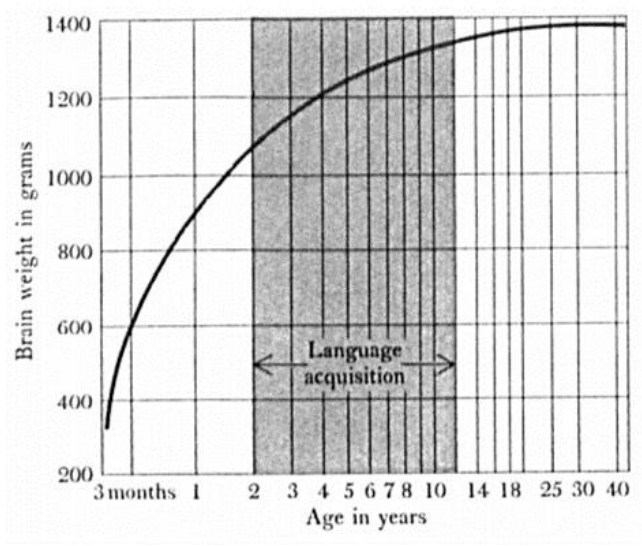

(b)

Figure 1. The research results of Eric Lennerberg: a) Data from 10 sample groups of children show sudden jump in vocabulary that consistently occurs around the third birthday; b) Period of maximum ability to acquire language appears to end at about the time the normal brain acquires its full weight

The other example, according to Murad (2006, p. 3), CPH predicts that if the acquisition of a far off language starts between the age of two and 12-13 (i.e., puberty), the process is going to be straightforward, and therefore the product will be complete (which is usually claimed to be a case in the acquisition of the first language). Moreover, through all tasks and age groups tested of Moyer (2004) showed that 3-5-year-old scored the lowest, and 12-15-year-old showed the most rapid acquisition in all skills tested: pronunciation, morphology, syntactic judgments, and listening comprehension.

\subsection{Research question}

The researchers carried out their research in different countries where English is not the first language, and those results have not been tested for Vietnamese learners. The 
questions are whether the above studies are correct for Vietnamese learners and whether this is a golden age for Vietnamese learners of English.

After performing survey and interview, the author found out that the golden age for Vietnamese learners of English fluctuates between 3 and under 18 years old, which is similar to the previous research.

\section{Materials and Methods}

This study is performed in two ways: the author used the data from the previous research on this topic, and Google Form to make an online survey as well as conducting interviews via Zalo and Messenger. The total of samples in this study is 72 people, and the data analysis tool is Excel 2016. All are conducted to find out the most suitable age for Vietnamese learners of English.

\subsection{Participants}

The author made an online survey via Google Form to survey 58 people. Most of them are the students of Ho Chi Minh City University of Food Industry (HUFI), the rest is the students at the other university and college in Ho Chi Minh City. There are 42 females and 16 males and currently, they live in Ho Chi Minh City. The age of starting to learn English is divided into 4 main groups, which are 3-8 years old, 8-12 years old, 12-18 years old, and over 18 years old, and the data in each group is 8 peers, 23 peers, 23 peers, and 4 peers, respectively. Additionally, 53.4\% of participants have studied English at the center and $46.6 \%$ studied English by themselves.

Besides, the author also conducted interviews with 14 people who are living in Ho Chi Minh city and started to learn English range 3-18 years old. There are 3 males and 9 females. Most of them are students majoring in English at HUFI, the rest are students of other majors at the other university in Ho Chi Minh city.

\subsection{Assessments and Measures}

\subsubsection{In online survey: The questionnaire includes 20 questions}

Item 1 is an open question aiming to collect the email address of participants.

Item 2 is an open question to collect the current age of participants.

Item 3 investigates the period of age that participants began to learn English. It is a close question with 5 choices: 3-8, 8-12, 12-18, over 18 years old, and others (if participants choose this one, they must write specific another range age that they began to learn English.)

Item 4 investigates whether participants have ever studied English at the center. This is also a close question with two choices, which are yes and no.

Item 5 surveys about the gender of participants. It is still a close question and only has 2 choices, which are female and male.

Item 6 aims to study whether participants had ever felt that it is so hard to listen and speak English when they began. It is also a close question with two choices: yes and no.

Item 7 is a grammar section with four questions in multiple-choice format, which aims to check the participants' knowledge about grammar.

Item 8 is a writing section and there are four questions in open question format, that is means the participants must write the correct answer to each question, which aims to examine the participants' writing skill.

Item 9 is a pronunciation section which four questions in multiple-choice format. In this section, the participants will choose a word that has different stress from the rest words, which tests the participants' pronunciation ability.

Item 10 is an open question to find out the time that participants spend completing three previous sections.

Item 11 is an open question and a final question of the online survey, which aims to collect the participants' ideas about the best period to learn English and the reason for that opinion. 
3.2.2. In the interview: the questionnaire includes nine open questions

132

Item 1 aims to ask the participants for their agreement to participate in the interview. Item 2 is like item 3 of the online survey, but the difference is that participants directly tell the author know the specific age when they begin to learn English.

Item 3 surveys whether the participants felt that it is difficult to pronounce English when beginning to learn English.

Item 4 studies the time the participants spend studying 50 vocabularies.

Item 5 aims to investigate how long the participants can remember that number of vocabularies, and after a week how many words they can remember.

Item 6 surveys if the participants have ever felt difficulty to learn and remember grammar structure.

Item 7 aims to study what percentage of English listening comprehension that the participants get currently.

Item 8 investigates if the participants are confident to communicate in English currently.

Item 9 has the content and the purpose which are completely like item 11 of the online survey.

\section{Results}

\subsection{The age differences in vocabulary learning}

Combining the results of the online survey and the interview, the author realized the differences between different ages in vocabulary learning, such as the time to learn 50 new words as well as how long they can remember it.... Table 1 shows the period age that Vietnamese people begin to learn English, specifically, there are four main groups, which are 3-8 years old, 8-12 years old, 12-18 years old, and over 18 years old with the percentage is $11.1 \%, 44.4 \%, 38.9 \%$, and $5.6 \%$ respectively.

\begin{tabular}{cc}
\hline Ages & How many people (account for ...\%) \\
\hline 3-8 years old & $8(11.1 \%)$ \\
8-12 years old & $32(44.4 \%)$ \\
12-18 years old & $28(38.9 \%)$ \\
Over 18 years old & $4(5.6 \%)$ \\
\hline
\end{tabular}

Table 1. The period age that Vietnamese learners start learning English

The author concludes from Table 1 that most of the Vietnamese learners began to study English from 8-12 years old, and there were very few people who start learning English from 3-8 years old and over 18 years old. The reason for this situation is that according to the Vietnam Education system, English is the compulsory subject from primary school, which is means when children are 6-11 years old. Currently, it is common that most rural schools start teaching English from grade three (8 years old), therefore, rarely parents let their children learn English before 8 years old because they think that is not good for their children's development. Until the last few years when English plays an increasingly important role and there are some reforms in the education system, the part of parents begin to encourage their children to learn English before 8 years old.

Table 2 shows the speed that ages learn 50 new words and the time that these vocabularies can be memorized in their brain. In this table, there are only have two main groups, which are under 12 years old and 12-under 18 years old, and the other norms are the time to study, how long it can be remembered, and the number of words remaining after a week. 


\begin{tabular}{ccccc}
\hline Ages & $\begin{array}{c}\text { The number } \\
\text { of the new } \\
\text { words }\end{array}$ & $\begin{array}{c}\text { The time to } \\
\text { study }\end{array}$ & $\begin{array}{c}\text { How long it can be } \\
\text { memorized in } \\
\text { brain }\end{array}$ & $\begin{array}{c}\text { The number of } \\
\text { words remaining } \\
\text { after a week }\end{array}$ \\
\hline $\begin{array}{c}\text { Under } 12 \text { years old } \\
\begin{array}{c}\text { From } 12 \text { to under } \\
18 \text { years old }\end{array}\end{array}$ & 50 & $\begin{array}{c}\text { About } 45 \text { minutes } \\
\text { to a day } \\
\text { About } 3 \text { hours to } \\
2-3 \text { weeks }\end{array}$ & $\begin{array}{c}2-3 \text { weeks maxi- } \\
\text { mum }\end{array}$ & At least 25 words \\
\hline
\end{tabular}

Table 2. The differences among ages in vocabulary learning

Based on the data in Table 2, it is realized that the children who began to learn English under 12 years old learn 50 vocabularies three times faster than the beginners from 12under 18 years old. Moreover, the period time these new words can be memorized in their brain and the words remaining after a week are also 2-3 times more than the people in the rest group. The reason is that there are many items after 12 years old, which affect the people's free time, for instance, many other subjects in secondary school and high school, for the people who over 18 years old, some people continue to learn at universities and another begins to work, of course, their free time will be limited more than the children.

\subsection{The differences in English listening comprehension ability}

Beside the differences in vocabulary learning, Vietnamese people who started learning English at different ages will have differences in English listening comprehension (ELC). When starting learning English, 93.1\% people felt that it is hard to listen and speak English, therefore, the author conducted an interview to study how their ELC ability currently. Table 3 demonstrates that English listening comprehension of two groups, which are under 12 years old and 12 -under 18 years old with units of percentage, and the figures are inferred from the responses of the interviewees.

\begin{tabular}{cc}
\hline Ages & ELC ability \\
\hline Under 12 years old & $5-75 \%$ \\
From 12 to under 18 years old & $40-85 \%$ \\
\hline
\end{tabular}

Table 3. English listening comprehension ability of two age groups

Although the speed of vocabulary learning of Vietnamese people who started learning English under 12 years old was faster than 12-under 18 years old, English listening comprehension ability of the group 12-under 18 years old was better than the other group. According to the answer of an interviewee who in group 12-under 18 years old, their ELC ability are very high because they have learned at many English centers before.

\subsection{Comparison in writing skill, grammar knowledge, and pronunciation ability}

Some factors that make English seem more difficult to beginners, such as pronunciation, grammar, syntactic, etc. Through the mini test in the online survey, the author realized that there is not a big difference between the two age groups when Vietnamese people started learning English, which are 3-12 years old and 12-under 18 years old in three respects: grammar knowledge, pronunciation ability, and writing skill. Table 4 shows how many people in each group did correctly four questions in each section.

\begin{tabular}{ccccc}
\hline Ages & $\begin{array}{c}\text { Number of } \\
\text { participants }\end{array}$ & $\begin{array}{c}\text { Grammar } \\
\text { section }\end{array}$ & $\begin{array}{c}\text { Writing sec- } \\
\text { tion }\end{array}$ & $\begin{array}{c}\text { Pronunciation } \\
\text { section }\end{array}$ \\
\hline $\begin{array}{c}\text { From 3 to 12 years } \\
\text { old }\end{array}$ & 31 & 9 & 5 & 10 \\
$\begin{array}{c}\text { From 12 to under 18 } \\
\text { years old }\end{array}$ & 27 & 16 & 8 & 11 \\
\hline
\end{tabular}


From the results of Table 4 can be seen that although the number of participants in group 1 (3-12 years old) was smaller than group 2 (12-under 18 years old), the number of people who did correctly four questions in three respects are more than group 1 . That is similar to Moyer's judgement (2004), which states that the people from 12-15-year-old showed the most rapid acquisition in all skills tested in his research: pronunciation, morphology, syntactic judgments, and listening comprehension.

\section{Discussion}

The present study was designed to find out the best time for Vietnamese people to learn English, aiming to reduce some troubles that can be met in the English learning process. As mentioned in the literature review, Golden Age is the period that people's brain can acquire best, and this study found the golden age for Vietnamese learners of English which will last from three to under 18 years old because it is easy for Vietnamese learners to perfect all English skills such as syntactic, morphology, pronunciation, etc. Specifically, the results of this study indicate that Vietnamese people who begin to learn English at different ages will have differences in some respects, for example, Vietnamese people who started learning English between three and 12 years old will be better in the speed of vocabulary learning and pronunciation, so they can sound like a native more. On the other hand, it is better in grammar structure, syntactic, or ELC ability if learning English from 12 to under 18 years old. Combining the two findings above, Vietnamese learners will have a better chance of mastering all English skills if they start studying from 3 to under 18 years old. This result explains that the brains of people in this age group are usually very good at memorizing and analyzing data, so they can memorize a large amount of vocabulary and for a long time. Besides, since the age of 12 , the human brain is almost complete, so it will be easier to absorb complex knowledge such as syntax and grammar structures.

This study is also the combination of the results of previous studies such as Lenneberg (1967), Moyer (2004), Murad (2006, p. 3). However, one unanticipated finding was that there were only four people who started learning English over 18 years old in the study and no one of them corrects all four questions in all three sections. Because the number is too small and not done correctly, it is impossible to compare the group under 18 and over 18 years old; this is also a limit of the study.

In future research, it is necessary to expand the scope of research such as increase the number of participants, add more essential questions to the online survey as well as conducting more in-depth interviews about the problem to be researched.

\section{Conclusions}

To sum up, when starting to learn English, there are inevitable barriers to language acquisition, therefore, it is easier for beginners to feel confused and stress, after that, they will be boring and give up. Barriers to English learning cannot be eliminated, but it is possible to reduce them by figuring out how to learn effectively and when it is best to learn. Due to this reason, this study is conducted to find out when the most suitable age is for Vietnamese to learn English. By consulting the previous research combine with conducting the online survey as well as the interview, the author concludes that the best period for Vietnamese to learn English lasts from 3-under 18 years old. This result is combined with three findings that are found from the study: 1) The age differences in vocabulary learning; 2) The differences in English listening comprehension ability; 3) Comparison in writing skill, grammar knowledge, and pronunciation ability.

Besides the success of the study in finding out the golden age for Vietnamese learners of English, the study still has some limits. Firstly, the participant of the study is too small, so it is difficult to reflect the reality completely correctly. Secondly, the findings in the results section have not yet led the reader to the final conclusion, so when reading here, it 
is easy for the reader to fall into a state of ambiguity and not understand the problem 256 raised.

\section{Patents}

Funding: This research received no external funding.

Conflicts of Interest: The authors declare no conflict of interest.

\section{Appendix}

Survey Question to find out the golden age:

1.Email address:

2.How old are you:

3.When did you start learning English?
a.3-8 b. $8-12$
c. $12-18$
d. over 18 years old

4.Have you ever learned English at the center?
a.Yes
b. No

5.Gender:

a.Female b. Male

6.Did you feel that it is very hard to listen and speak English when you began learning?
a.Yes
b. No

A. SECTION 1: GRAMMAR

1.The students to be at school at 3 p.m.
a.Told
b. have told
c. were told
d. tell.

2.He bought all the books are needed for the English course.

3. we could not go out because it rained.
a.Fortunately
b. Fortunate

c. Unfortunately d. Unfortunate

4.The shirt in the window was

a.Too b. such

c. enough d. so expensive for me to buy.

\section{B. SECTION 2: WRITING}

1.Mary is watering the roses in the garden.

$\Rightarrow$ The roses in the garden by Mary.

Answer:

2.If you do not practice every week, you will not be a stronger swimmer.

$\Rightarrow$ You will not be a stronger swimmer unless every week.

Answer:

3.Why don't you join a swimming team?

$=>$ If I were you, join a swimming team.

Answer:

4."I haven't got time to play tennis often", she said.

$\Rightarrow$ She said she enough time to play tennis often.

Choose the best answer:

1.Look for the word with different stresses from the rest.

a.Confidence b. Celebrate c. Effective d. Reasonable

2.Look for the word with different stresses from the rest.

a.Pesticide b. maintenance c. messenger d. consumption

3.Look for the word with different stresses from the rest.

a.Benefit b. average c. badminton $d$. ambition

4.Look for the word with different stresses from the rest.
a.Embarrass
b. Business c. dominant
d. decorate 
7.How long did it take you to complete this test?

In your opinion, when is the best period for Vietnamese learners of English? WHY?

307

308

309

\section{References}

1. Birdsong, D. (1999). Second Language Acquisition and the Critical Period Hypothesis. New Jersey: Routledge. Language and Literature Studies, IX(4), 231-243.

4. Nghi, T. T. (2016). Applying the "Flipped Classroom Model" for teaching a foreign language. Journal of Foreign Language Studies, $3(46), 67-72$.

5. Phuc, T.H, Thang, N.T., Nghi, T.T. (2019). A Cognitive study of Nonlinguistic Factors Affecting the use of Prepositions by Vietnamese Native Speakers. International Journal of Applied Linguistics and English Literature, VII(1), 147-158.

6. Moyer, A. (2004). Age, Accent, and Experience in second language acquisition. Great Britain: Multilingual Matters Ltd.

7. Murad, J. (2006). Age as a Factor in Second Language Acquisition. Germany: GRIN Verlag.

8. Penfield, W., \& Roberts, L. (1959). Speech and Brain Mechanisms. New Jersey: Princeton University Press.

9. Singleton, D. M., \& Ryan, L. (2004). Language Acquisition: The Age Factor. Great Britain: Multilingual Matters Ltd 